\title{
Quality Facets of a UX LMS Affective Model for the Design and Evaluation of Learning Management Systems
}

\author{
Azham Hussain ${ }^{1}$, Emmanuel O.C. Mkpojiogu², Nurnasran Puteh ${ }^{\text {*3 }}$ \\ ${ }^{1,2,3}$ School of Computing, Universiti Utara Malaysia, 06010 UUM, Sintok, Malaysia \\ ${ }^{2}$ Department of Computer and Information Technology, Veritas University, Abuja, Nigeria \\ Corresponding author: ${ }^{3 *}$ nurnasran@uum.edu.my
}

Article History: Received: 10 November 2020; Revised: 12 January 2021; Accepted: 27 January 2021; Published online: 05 April 2021

\begin{abstract}
This study looked into extant literature to elicit a mapping relationship for the affective component of Bloom's learning taxonomy and a theoretical affective model for the design and evaluation of the affective experiences of users of and learners on learning management system (LMS) platforms. The study found that no prior affective model exists specifically for the design and evaluation of the affective experiences of LMS users. The study then mapped the affective component of the Bloom's taxonomy of learning with the conceptual affective model and captured corresponding suitable quality facets/dimensions that influence and contribute to the model. This model is particularly appropriate for the design and evaluation of the affectivity of LMS platforms.
\end{abstract}

Keywords:LMS affective model, quality facets, learning management systems

\section{Introduction}

A virtual learning environment (VLE) is an online learning platform that enables students to interact with their teachers, fellow students and learning contents via an interactive interface. Learning in such environment focuses on the students' activity, and student engagement in the learning process (Sucipto et al., 2017). An instance of a VLE is a learning management system (LMS). An LMS is a learning medium that is mediated by technology, particularly, the Internet. It is a web-based application used to manage electronic learning, and mobile learning activities. It facilitates the administration, tracking, documentation, reporting, and delivery of learning contents. It has the following facilities: authentication, learning, communication, collaboration, assessment and accountability (Macnaughton \& Medinsky, 2015). The use of these applications have increased in institutions of higher learning as they assist instructors to design, share and deliver learning materials and supports students to individually and collaboratively learn on the platforms (Redwan et al., 2016; Van den Dool, 2019). LMS assists teachers with the management of their courses. It also allows for the provision of pedagogical contents, communication, collaboration, and sharing to aid learning (Septiani et al., 2017; Ouadoud, Chafiq \& Chkouri, 2018). It provides an avenue for classroom materials or activities to be shared easily. It is a portal that enables lecturers and students to interact individually and in discussion groups outside the physical classroom (Anand \& Eswaran, 2018). There are a number of LMS platforms among which Moodle (2019), Blackboard (2019), and Sakai (2019) are the most adopted (Liyanage, Gunawardena \& Hirakawa, 2014). Moodle however is the most favored as $65 \%$ of institutions are using it as their LMS tool. Next is Blackboard with $12 \%$ (Anand \& Eswaran, 2018). A survey conducted in Europe in 2016 involving 1604 educational institutions with reference to the use of LMS tools revealed that $63 \%$ of the institutions in Europe were using Moodle (Hill \& Feldsten, 2016). A VLE supports learners achieving their learning goals (Hussain et al, 2016a; 2016b; Hussein et al., 2019a; 2019b; Mkpojiogu et al., 2016; 2018).

The affective model for the design and evaluation of the UX of LMS platforms was conceptualized and developed from the affective component of the Bloom's learning taxonomy (Bloom, 1956). This affective model explains the affective organismic self of users of and learners on LMS. The affective organism influenced by design factors (stimuli) that drive the experiential reactions/responses of the learners and users of LMS platforms (Mehrabian \&Russell, 1974). The affective model is related to the emotions and feelings of the users of/learners on the LMS platform (Hatami, 2016). The model consist of the emotional (Gorbunovs et al., 2017; Green \& Batool, 2017) organism of the users that incorporate the feelings of happiness and wellbeing (Minge, Wagner \& Kuhr, 2016), joy (Noorhidawati et al., 2015; Minge, Wagner \& Kuhr, 2016), enjoyment (Kahveci \& Orgil, 2015; Dingler, 2016), self-esteem (Green \& Batool, 2017), love (Sheldon et al., 2001), curiosity (Dingler, 2016; Green \& Batool, 2017), adventure (Takatalo et al., 2008), surprise (Minge, Wagner \& Kuhr, 2016), confidence (Gorbunovs et al., 2017) and discovery (Kraleva et al., 2019) etc. that intrinsically motivates the learners' use (Althobaiti \& Mayhew, 2016), continual usage, and active involvement in the LMS platform. These qualities are indispensable for the learners' personal growth and transformational sense of self-functioning and fulfillment (Maslow, 1954). 
The stimuli that affects this affective organism include: i) inspiring (Minge, Wagner \& Kuhr (2016): an inspiring LMS platform will stimulate positive emotions in learners; ii) exciting (Minge, Wagner \& Kuhr, 2016): LMS platforms that are exciting to learners will spur in them a good feeling about the platform, enhance their wellbeing and promote in them a positive energy to learn; iii) interesting (Green \& Batool, 2017): LMS platform and learning contents that are interesting encourages positive feeling in learners/users and makes them to actively participate with focused attention in the interactive learning activities; iv) attractive (Gorbunovs et al., 2017): LMS interface that are visually appealing and learning contents that are attractive charms users and encourages positive emotions that pulls learners towards the platform and produces active participatory involvement in them in the learning activities on the platform; v) novel (Santoso et al., 2017): a learner-centered learning tends towards learners active and independent participation in the learning process that leads to personal discovery of new knowledge by learners. It makes learners to interpretatively make sense of the knowledge they discovered on the platform. This implies that the platform must offer contents that are novel and the interface design itself should be novel too. Novel LMS produces the joy of interaction in learners; vi) pleasurable (Guimaraes et al., 2017): interaction in the LMS platform should be delightful, fun and pleasurable and with this, the emotion of users will be enhanced propelling an active and immersive participation in them (Althobaiti \& Mayhew, 2016); vii) challenging (Althobaiti \& Mayhew, 2016): a simply but challenging LMS interface and content spurs learners efforts and energy reactivation to surmount the supposed challenge. Challenging LMS stimulates commitment in learners to learn; vii) fascinating (Minge, Wagner \& Kuhr, 2016): a fascinating LMS is captivating and draws and sustains learners' attention span throughout the learning process and activities. These stimuli activate the valence in users and produces positive energy in them for learning and active involvement in the learning activities on the LMS platform. From the literature review done, there is no affective model in existence that is used for the design and evaluation of the affective experiences of users of learning management systems. This gap in knowledge instigated the current study.

\section{Methodology}

This research utilized a literature mapping strategy to conceive and develop a UX affective model for the design and evaluation of the affective aspects of the experiences of users of LMS products. In the study, to facilitate the mapping, a literature survey was conducted. Suitable and appropriate articles were downloaded and analyzed. This was followed by a keen extraction of required information from the downloaded texts. The steps employed are as follows (Figure 1): i) download of appropriate literature materials related to the modeling of the affective model of LMS platforms for design and evaluation of users' affective experiences on the platform; ii) synthesize and analyze the downloaded texts; iii) extract required information from the literature sources that pertain to the modeling of the affective experiences of LMS users; ix) conceptualize the UX affective model; v) propose the UX affective model.

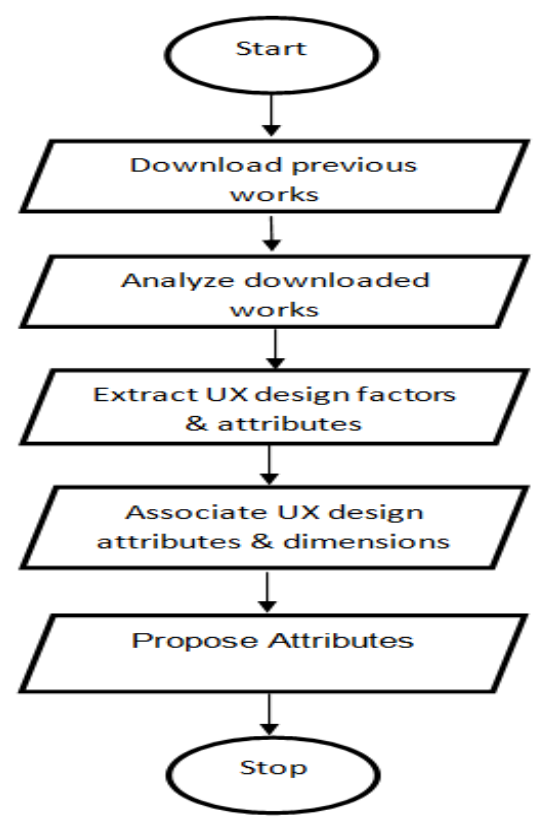

Figure 1. Study Process 


\section{Results}

The results of this study uncovered a gap with respect to the non-existence of any custom affective model for the design and evaluation of the affective experience of learners using learning management system platforms. The study also found that there is a mapping relationship between the affective component of the Bloom's taxonomy of learning and the UX LMS affective model. The study then further elicited the quality facets that match, influence and contribute to the UX LMS affective model.

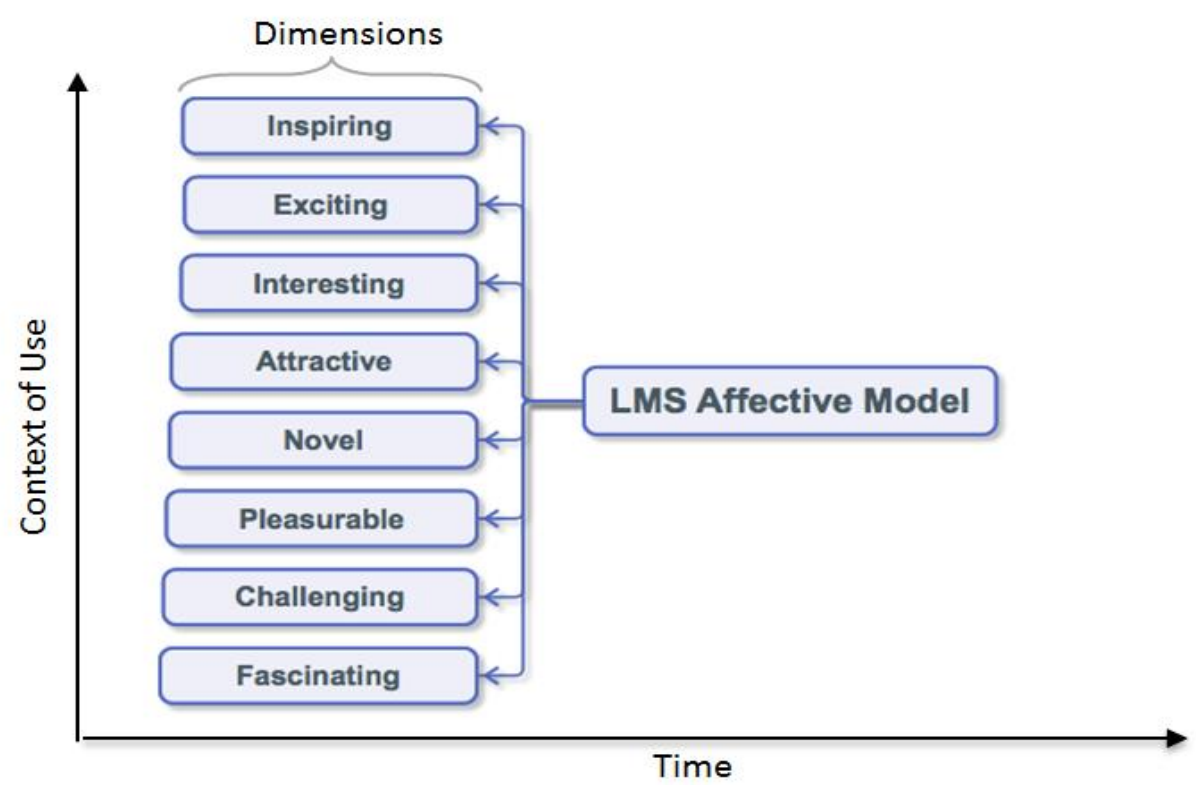

Figure 2. A LMS Affective Model

Table 1. Dimensions and Quality Facets of an Affective Model for LMS UX Design and Evaluation

\begin{tabular}{|c|c|}
\hline $\begin{array}{l}\text { Model } \\
\text { Affective } \\
\text { (Sonmez, 2017; Ajumunisha et al., 2018) }\end{array}$ & Quality Facets \\
\hline \multirow[t]{8}{*}{$\begin{array}{l}\text { Affective } \\
\text { (Sonmez, 2017; Ajumunisha et al., 2018) }\end{array}$} & $\begin{array}{l}\text { Inspiring } \\
\text { (Sucipto et al., 2017) }\end{array}$ \\
\hline & $\begin{array}{l}\text { Exciting } \\
\text { (Minge, Wagner \& Kuhr, 2016) }\end{array}$ \\
\hline & \begin{tabular}{l} 
Interesting \} $\\
{\text { (Green \& Batool, 2017) }}$ \\
\hline & $\begin{array}{l}\text { Attractive } \\
\text { (Sailer et al., 2015) }\end{array}$ \\
\hline & $\begin{array}{l}\text { Novel } \\
\text { (Santoso et al., 2017) }\end{array}$ \\
\hline & $\begin{array}{l}\text { Pleasurable } \\
\text { (Minge, Wagner \& Kuhr, 2016) }\end{array}$ \\
\hline & $\begin{array}{l}\text { Challenging } \\
\text { (Ertemel, 2017) }\end{array}$ \\
\hline & $\begin{array}{l}\text { Fascinating } \\
\text { (Minge, Wagner \& Kuhr. 2016) }\end{array}$ \\
\hline
\end{tabular}
\end{tabular}

The affective model deals with the feelings, mood, passion, and emotional state and reaction elicited in learning management system platform interaction. Users/learners as humans have feelings which they express as they use the LMS platform. The affective dimension of LMS platform can be measured with the following bipolar valences:

i. Happiness: This quality describes how happy or sad learners are while learning on the LMS platform. ii. Joy: This quality describes how joyful learners are while learning or interacting with the LMS platform. It shows learners feeling of enjoyment on the LMS platform.

iii. Wellbeing/Wellness: This quality explains learners' feeling of wellness as they interact with or learn the LMS platform. 
iv. Love: This quality describes how much learners love or hate interacting with or learning on the LMS platform.

v. Hope: This quality described how much the LMS platform inspires hope and courage to learn on the LMS platform.

vi. Curiosity: This quality explains how the LMS platform makes learners curious and eager to learn on the LMS platform.

vii.Adventure: This quality describes how the LMS platform makes learners to go into learning adventure, wanting to know new things.

viii. Delightfulness: This quality explains how delightful and satisfying an LMS is to learners.

ix. Passion: This quality describes how the LMS platform makes learners passionate and committed to learning activities on the platform.

x. Surprise: This quality shows the extent of surprise learners are on/with the LMS platform they are interacting with or learning on. This explains the wow effect such platform has on them.

xi. Discovery: This quality indicates how much the LMS platform helps learners to discover knowledge independently in their self-learning endeavors.

xii.Confidence: This quality shows the level of confidence to learn or in learning that the LMS platform breathes on learners interacting with it.

There are nine attributes/dimensions that activate/arouse users/learners' affective state on the LMS platform. They are as follows:

i. Inspiring: This attribute explains how inspiring a learning management system platform is to users/learners. Learners are more engrossed in the learning activities of an LMS that inspires them. Thus, the inspirational level of an LMS influences the affective model of an LMS.

ii. Exciting: This is a quality that defines how excited users and learners of LMS are while interacting with the platform. An LMS that is exciting engages users/learners in their learning activities on the platform. Thus, an exciting LMS has impact on the affective state of learners.

iii. Interesting: An interesting LMS prolongs and sustains the attention and interactive activities of users and learners on the LMS platform. Learners tend to be more actively involved on learning platforms that is interesting to them. Hence, this criterion affects the affective organism of users/learners of LMS platforms.

iv. Novel: A novel LMS with new contents and creative interfaces is the delight of users/learners. Users/learners are drawn to interact with learning platforms they perceive has novelty, originality, uniqueness and innovativeness. Therefore, such platforms impacts on the affectivity of users/learners.

v. Attractive: Attractive quality influences the affective state of users/ learners on LMS platforms. Users/learners are stimulated and captivated to learn with or interact with LMS when such platform is visually attractive and appealing to them. This attribute stimulates users/learners to learn with joy, interest and enthusiasm.

vi. Pleasurable: A pleasurable LMS is a stimulating platform for learning. Such platform supports learning with fun and amusement. It makes learners happy and joyful while learning as it entertains and gives them pleasure in the learning process.

vii.Challenging: This quality attribute defines the degree to which an LMS platform challenges learners to learn irrespective of difficulties faced. Difficulties in learning are seen as surmountable and the tensions encountered are courageously and pleasurably perceived. Challenge has impact the affective model of LMS platforms.

viii. Fascinating: A fascinating LMS is a learning platform that captivates, intrigues, and enthralls users/learners to interact with and learn on. Such platform captures their gaze, attention and focus. This quality makes users/learners to be actively absorbed in learning activities as they are drawn by the fancy of the platform. Thus, this quality affect users/learners affective organism.

ix. Personal: A personal or personalized LMS is an LMS that is tailored to the individual needs of every learner. It is a learning platform that supports independent, self-regulated and self-motivated learning. On such platforms, learners are able to and feel they can construct and discover their own knowledge through sense-making. Personal or customized learning platforms affect learners' affective reactions and responses.

Following these results, the UX LMS model was conceptualized. This paper thenceforth proposes the adoption of the model specifically for the design and evaluation of the affectivity of the LMS platforms.

\section{Conclusion}

This paper examines prior literature to capture a mapping association between the affective component of Bloom's taxonomy of learning and a conceptual affective model for the design and evaluation of the affective experiences of users of and learners on LMS platforms. First, the study discovered that no previous affective 
model existsparticularly for the design and evaluation of the affective experiences of LMS users. The study then mapped the affective component of the Bloom's learning taxonomy with the theoretical affective model and elicited appropriate quality facets and dimensions that contribute to the model. This model is specifically suitable for the design and evaluation of the affectivity of LMS platforms.

\section{References}

1. Ajumunisha, A., Begam, A., \& Tholappen, A. (2018). Psychomotor domain of Bloom's taxonomy in teacher education. Shanlax International Journal of Education, 6 (3), 11-14.

2. Althobaiti, M.M., \& Mayhew, P. (2016). How usable are the learning management systems? The users have their say. EAI Endorsed Transactions on E-Learning, 3(11), 1-9.

3. Anand, A., \& Eswaran, S. (2018). A survey of open source learning management systems.Anale Seria Informatica, XVI (1), 185-188

4. Blackboard (2019). Blackboard educational technology platform.http://www.blackboard.com

5. Dingler, T. (2016). Cognitive-aware systems to support information intake and learning. PhD Thesis. Institut fur Visualisierung und Interative Systeme der Universitat Stuttgart.

6. Ertemel, A.V. (2017). The role of gamification in online learning management system. $7^{\text {th }}$ International Conference of Strategic Research on Social Science and Education (ICoSReSSE), 13-15 October 2017, Antalya, Turkey (pp. 239-247)

7. Gorbunovs, A., Timsans, Z., Zuga, B., \& Zagorskis, V. (2017). Conceptual design of the new generation adaptive learning management system. International Journal of Engineering \&Technology, 7 (2.28), 129-133.

8. Green, Z.A., \& Batool, S. (2017). Emotionalized learning experiences: tapping into the affective domain. Evaluation and Program Planning, 62, 35-48.

9. Guimaraes, M.P., Alves, B., Martins, V.F., Baglie, L.S.S., Brega, J.R., \& Dias, D.C. (2017). Embedded augmented reality applications into learning management systems. Lecture Notes in Computer Science.

10. Hatami, J. (2016). Smart View: a study on students' attitude toward employing smart glasses as a medium of e-learning. Master Thesis. Department of Informatics, Umea University.

11. Hills, P., \& Feldstein, M. (2016). Bits \& bytes new release of European LMS market report, $e$ Literate, Dec., http://mfeldstein.com/new-release-european-lms-market-report/

12. Hussein, I, Hussain, A., Mkpojiogu, E.O.C., Nathan, S.S., \& Zaaba, Z.F. (2019a). The knowledge of human-computer interaction (HCI) and user experience design (UXD) in Malaysia: an analysis of the characteristics of an HCI-focused conference. International Journal of Innovative Technology and Exploring Engineering, 8(8S), 483-490.

13. Hussein, I., Mkpojiogu, E.O.C., \& Hussain, A. (2019b). A focus group assessment of participants' UX knowledge and their motivations for participating in a UXD community of practice.Journal of Advanced Research in Dynamical and Control Systems (JARDCS), 11(05-SI), 1496-1499.

14. Hussain, A., Mkpojiogu, E.O.C., \& Kamal, F.M. (2016a). Antecedents to user adoption of interactive mobile maps. Journal of Telecommunication, Electronic \& Computer Engineering (JTEC).8(10), 41-45.

15. Hussain, A., Mkpojiogu, E.O.C. \& Yusof, M.M. (2016b). The effects of proposed software product's features on the satisfaction and dissatisfaction of potential customers. Proceedings of the $1^{\text {st }}$ International Conference on Applied Science and Technology (ICAST'16), Kedah, Malaysia, AIP Conf. Proc.1761 (1), 020052, http://dx.doi.org/10.1063/1.4960892.

16. Kahveci, M., \& Orgil, M. (Eds.) (2015). Affective Dimensions in Chemistry Education. NewYork: Springer Heidelberg.

17. Kraleva, R., Sabani, M., Kralev, V. (2019). An analysis of some learning management systems. International Journal on Advanced Science Engineering Information Technology, 9(4), 11901198.

18. Liyanage, M.P.P., Gunawardena, K.S.L., \& Hirakawa, M. (2014).Using learning styles to enhance learning management systems. Int. J. on Advances in ICT for Emerging Regions, 7(2), 1-10.

19. Macnaughton, S., \& Medinsky, M. (2015). Staff training, onboarding, and professional development using a learning management system. Partnership: The Canadian Journal of Library and Information Practice and Research, 10 (2), 1-8.

20. Maslow, A. (1954). Motivation and personality. New York: Harper \&Row.

21. Mehrabian, A., \& Russell, J.A. (1974). An Approach to Environmental Psychology, MA, Cambridge: MIT Press. 
22. Minge, M., Thuring, M., Wagner, I., \& Kuhr, C. (2016). The meCUI questionnaire. A modular tool for measuring user experience. Proceedings of the $7^{\text {th }}$ Applied Human Factors and Ergonomics Society Conference, 2016. Switzerland: Springer International Press, pp. 115-128.

23. Mkpojiogu, E.O.C., Hashim, N.L., \& Adamu, R. (2016). Observed demographic differentials in user perceived satisfaction on the usability of mobile banking applications. Proceedings of the $8^{\text {th }}$ Knowledge Management International Conference (KMICe'16), Chiang Mai, Thailand, 29-30 August 2016. ISBN: 978-967-0910-19-2; eISBN: 978-967-0910-20-8; pp. 263-268.

24. Mkpojiogu, E.O.C., \& Hussain, A. (2018). Assessing the influence of self-reported requirements importance on the perceived quality of proposed software products.ICAST 2018, AIP Conf. Proc. 2016, 020091, https://doi.org/10.1063/1.5055493

25. Moodle (2019). Moodle learning management system. http://www.moodle.org

26. Noorhidawati, A., Ghalebandi, S.G., \& Hajar, R.S. (2015). How do young children engage with mobile apps? Cognitive, psychomotor, and affective perspective.Computer \& Education, 87, 385395

27. Ouadoud, M., Chafiq.,\& Chkouri, M.Y. (2018). Designing an IMS-LD model for disciplinary information space of learning management system. In Proc. of the ACM $3^{\text {rd }}$ Int'l Conference on Smart City Applications (SCA'18), October 10-11. Tetouan, Morocco: ACM

28. Redwan, N.M., Senousy, M.B., \& Riad, A.D.M. (2016). Approaches for managing uncertainty in learning management systems. Egyptian Computer Science Journal, 40 (2), 1-10.

29. Sailer, C., Schito, J., Kiefer, P., \& Raubal, M. (2015). Teachers matter: challenges of using a location-based mobile learning platform. Doi:10.13140/RG.2.1.1403.9767

30. Sakai (2019). Sakai. http://www.sakaiproject.org/

31. Santoso, H., Schrepp, M., Hinderks, A., \& Thomaschewski, J. (2017). Cultural differences in the perception of user experience. Mensch und Computer, Tagungsband

32. Septiani, A.P., Suwawi, D.D.J., \& Herdiani, A. (2017). Interactive and collaborative platform implementation on learning management system.2017 $5^{\text {th }}$ International Conference on Information and Communication Technology (ICoICT). IEEE, pp. 440-445.

33. Sheldon, K. M., Elliot, A. J., Kim, Y., \& Kasser, T. (2001). What is satisfying about satisfying events? Testing 10 candidate psychological needs.Journal of personality andsocial psychology, $80(2), 325$

34. Sonmez, V. (2017). Association of cognitive, affective, psychomotor and intuitive domains in education, sonmez model. Universal Journal of Educational Research, 5(3), 347-356.

35. Sucipto, T.L.A., Efendi, A., Hanif, H.N., \& Budiyanto, C. (2017). The influence of learning management technology to student's learning outcome. International Journal of Pedagogy and Teacher Education (IJPTE), 1(1), 11-18.

36. Takatalo, J., Häkkinen, J., Kaistinen, J., \& Nyman, G. (2008).Measuring user experience in digital gaming: Theoretical and methodological issues. Electronic Imaging 2007, (6491), 649402649413

37. Van den Dool, J. (2019). Technology and artistic learning: the role of a learning management system in performing arts education. 